\title{
PERCEPÇÕES DE EDUCADORES SOCIAIS SOBRE TRABALHO, ADOLESCÊNCIAS E PRÁTICAS EDUCATIVAS
}

\section{SOCIAL EDUCATORS PERCEPTIONS ABOUT WORK, ADOLESCENCES AND EDUCATION PRACTICES}

\author{
Fernanda Pereira Calabar ${ }^{1}$ \\ Priscila Sá da Silveira ${ }^{2}$ \\ Vanessa Barbosa Romera Leme ${ }^{3}$
}

\section{RESUMO}

A institucionalização de crianças e adolescentes pode favorecer a manifestação de distúrbios psicológicos. Por meio das interações positivas com os educadores sociais é possível que essa condição de vulnerabilidade possa ser superada e/ou minimizada. Este estudo qualitativo teve como objetivo investigar as percepções dos educadores sociais sobre o trabalho e relações com os adolescentes. Participaram 17 educadores (13 homens) de três instituições públicas da cidade do Rio de Janeiro. Foram realizados quatro grupos focais e coletadas informações com os seguintes instrumentos (1) Questionário de Caracterização; (2) Classificação Socioeconômica; (3) Roteiro Temático do Grupo Focal. Foram encontrados três temas abrangentes: "Adolescências" (n=186); "Trabalho do educador social" ( $n=95)$; "Práticas de sociabilização" $(n=79)$. As informações contribuirão para fomentar ações em futuras intervenções com este público, além de políticas públicas e práticas preventivas de promoção de saúde.

Palavras-chave: Grupo focal; Educador social; Acolhimento.

\section{ABSTRACT}

The institutionalization of children and teenagers can lead to the manifestation of psychological disorders. Through positive interactions with social educators, this vulnerability condition can be overcome and/or minimized. This qualitative study aimed to investigate the perceptions of social educators about working and relationships with adolescents. Research participants include 17 educators (13 men) from three public shelters in Rio de Janeiro. Four focus groups were carried out, and information was collected using the following instruments: (1) Characterization Questionnaire; (2) Socioeconomic Classification; (3) Focus Groups' Thematic Script. Three broad themes were identified: "Adolescences" (n=186), "Work of the social educator" $(n=95)$,

\footnotetext{
${ }^{1}$ Doutoranda do Programa de Pós-Graduação em Psicologia Social da Universidade do Estado do Rio de Janeiro - UERJ. Mestra em Psicologia pelo Programa de Pós-Graduação em Psicologia, da Universidade Federal Rural do Rio de Janeiro (PPGPSI-UFRRJ). e-mail: nandacalabar@yahoo.com.br

2 Doutoranda do Programa de Pós-Graduação em Psicologia Social da Universidade do Estado do Rio de Janeiro - UERJ (2018). Mestra em Psicologia Social pela Universidade do Estado do Rio de Janeiro. e-mail: priscilasadasilveira@gmail.com

${ }^{3}$ Atualmente é Professora Adjunta no Departamento de Cognição e Desenvolvimento no Instituto de Psicologia e no Programa de Pós-Graduação em Psicologia Social da Universidade do Estado do Rio de Janeiro (UERJ). Doutora em Psicologia pela Faculdade de Filosofia, Letras e Ciências Humanas da Universidade de São Paulo. email: vanessaromera@gmail.com
} 


\section{Revista \\ Debates Insubmissos}

"Sociability practices" (n=79). The information will help to promote actions in future interventions with this audience and public policies and preventive practices for health promotion.

Keywords: Focus group; Social educator; Shelter.

\section{INTRODUÇÃO}

Adolescentes que vivem em acolhimento institucional podem passar por situações de cuidados desfavoráveis por estarem privados dos cuidados parentais e familiares por longo período de tempo (CAVALCANTE; MAGALHÃES; PONTES, 2009). Em situações de privação material e emocional severas, os acolhidos podem ter seu desenvolvimento comprometido, gerando riscos ao processo de estruturação de sua personalidade, à sociabilização, como também ao desenvolvimento psicológico (SALINA-BRANDÃO; WILLIAMS, 2008).

De acordo com o Art. 98 do ECA (BRASIL, 1990) e, conforme as "Orientações Técnicas: Serviços de Acolhimento para Crianças e Adolescentes” (BRASIL, 2009), o serviço de acolhimento institucional tem caráter provisório e excepcional, não podendo exceder 18 meses. Considerado o último recurso em situações de grave risco e vulnerabilidade social, o acolhimento institucional deve ser evitado sempre que possível, caso haja a viabilidade de manutenção da convivência familiar (BRASIL, 2009).

Segundo o Conselho Nacional de Justiça (CNJ, 2021), em todo o Brasil no ano de 2021, 30.956 crianças e adolescentes viviam em algum dos 4792 serviços de acolhimento. Desses, a maioria se declarou parda (20,6\%), 13,5\% brancas, 6,3\% pretas e 59,2\% não informaram a raça. Em relação ao sexo, 50,5\% eram meninos e sobre a faixa etária 46,74\% tinham mais de 12 anos. O estado do Rio de Janeiro é o quinto estado com mais acolhidos em todo território nacional, com 2.124 atendidos em 176 instituições, estando detrás de São Paulo (8.467), Rio Grande do Sul (3.590), Minas Gerais (3.438) e Paraná (2.520).

Os motivos mais prevalecentes para o encaminhamento dos adolescentes para instituições acolhedoras são a exploração ou abuso sexual, trabalho infantil, condição de rua, dependência química, falecimento dos pais, violência doméstica e/ou física, negligência e a 
saúde mental dos pais (FURLAN; SOUZA, 2013). Assim, os adolescentes podem vivenciar, dentro da instituição, os mais diversos momentos e expectativas, seja esperando o retorno para família biológica ou aguardando a colocação em famílias substitutas (MACHADO, 2011). Nesse caso, ao realizar estudos sobre as instituições de acolhimento é necessário levar em consideração a presença ou a ausência de fatores de proteção e de risco na entidade (SALINABRANDÃO; WILLIAMS, 2008).

A presença de fatores de risco, que envolvem adolescentes no contexto de acolhimento institucional é descrita como preconceito (BUFFA; TEIXEIRA; ROSSETTI-FERREIRA, 2010), experiência de maus tratos como negligência, violência, abandono (CALCING; BENETTI, 2014), imagens sociais negativas (BERSCH; YUNES; GARCIA, 2020; CRUZ; PEDROSO; COSTA, 2018; PATIAS; SIQUEIRA; DELL'AGLIO, 2017), precariedade da oferta de instituições e serviços públicos (FONSECA et al., 2013). Por serem considerados um grupo social mais vulnerável, marcado por problemas biopsicossociais, por desigualdades sociais, violação de direitos e opressões, observou-se que experiência de maus tratos e imagens sociais negativas, podem influenciar no desenvolvimento e socialização dos adolescentes em acolhimento com sua família, comunidade e funcionários da instituição (CALCING; BENETTI, 2014; CRUZ; PEDROSO; COSTA, 2018).

Já os fatores de proteção, por outro lado, contribuem para que o espaço da instituição se estabeleça como promotor de educação de qualidade (WENDT; DELL'AGLIO, 2018). Destaca-se a presença de vínculos afetivos entre educadores, adolescentes e equipe técnica (CASSARINO-PEREZ; MONTSERRAT; SARRIERA, 2020; GUIMARAES; NETO, 2015; RODARTE et al., 2015; SILVA; BARROS, 2018; VIEIRA; COUTINHO, 2019), desenvolvimento da autonomia, socialização (CRUZ; PEDROSO; COSTA, 2018) e promoção da resiliência (GONÇALVES; CAMARNEIRO, 2018; SANTOS; SANTANA; SOUZA, 2020). A instituição como lugar de proteção (ARPINI, 2003), deve focalizar em práticas que estimulem a individualidade, o desenvolvimento linguístico, o direito de ouvir, ser ouvido, expressar habilidades e a promoção de reflexões sobre suas realidades (SILVA; BARROS, 2018). Compreender os fatores de proteção e de risco que envolvem o contexto do acolhimento 


\section{Debates Insubmissos}

Revista

institucional, os educadores sociais e suas relações com adolescentes acolhidos pode contribuir para ações efetivas de prevenção e promoção de saúde.

A definição de prevenção tem se desenvolvido ao longo do tempo a partir dos conceitos de Caplan, em 1964, que subdividiu a prevenção em três seguimentos: primária, secundária e terciária (ABREU; BARLETTA; MURTA, 2015). Para Weisz, Durlak, Sandler (2005) práticas de prevenção dizem respeito a programas destinados a promover ativamente a saúde mental por meio da expansão do conhecimento, o fortalecimento das habilidades de enfrentamento e o enriquecimento dos recursos de apoio. Consequentemente, programas de prevenção para educadores, como treinamento de habilidades sociais educativas, sessões com técnicas de manejos de estresse, habilidades de enfrentamento ou manejo de conflitos poderão refletir em benefícios significativos para a redução das taxas de futuros problemas sociais, comportamentais e acadêmicos de crianças e adolescentes acolhidos. Abreu et al. (2015) afirmam que intervenções preventivas buscam focalizar, de modo geral, nos fatores de risco (redução) ou fatores de proteção (ampliação), com o objetivo de reduzir futuras incidências de problemas, sejam de ajustamentos, emocionais, comportamentais, promovendo a construção de competências associadas a saúde mental.

À vista disto, de acordo com a Carta de Ottawa, de novembro de 1986, a promoção da saúde envolve fatores positivos em saúde, enfatizando os recursos pessoais e sociais, além de um estilo de vida saudável, mas na direção de um bem-estar global. Neste caso, a promoção da saúde não é responsabilidade exclusiva do setor saúde, mas envolve um processo de capacitação da comunidade em ser atuante na melhoria de sua qualidade de vida e saúde (WHO, 1986) como um conjunto de estratégias e métodos de produzir saúde, no âmbito individual e coletivo (BRASIL, 2014). Segundo Weiz, Durlak e Sandler (2005), intervenção de promoção de saúde tem por objetivo desenvolver habilidades e disponibilizar recursos para que os indivíduos enfrentem adversidades, sejam pessoais ou do contexto ao qual estão inseridos. Assim, intervenções de promoção de saúde com educadores sociais poderão favorecer desfechos positivos como vínculos afetivos, sociais, bem-estar e qualidade de vida em adolescentes acolhidos.

\section{O EDUCADOR SOCIAL}


A profissão de educador social se estabelece em diferentes medidas socioeducativas no Brasil e ocorre fora do contexto escolar, no atendimento às pessoas e comunidades em situação de risco e vulnerabilidade. Envolve os segmentos sociais prejudicados pela exclusão social seja mulheres, crianças, adolescentes, negros, indígenas e homossexuais. Além de realizar atividades socioeducativas em regime fechado, semiliberdade e meio aberto para adolescentes e jovens envolvidos em atos infracionais, população carcerária, pessoas com deficiência, pessoas com necessidades educativas especiais, dependentes de drogas e terceira idade (MACHADO; MACHADO, 2014).

O educador social de uma instituição acolhedora para crianças e adolescentes é parte integrante da equipe técnica composta, geralmente, por um coordenador de nível superior, um assistente social, um psicólogo e um auxiliar de educador. O número de cada equipe poderá variar de acordo com o tamanho e com as demandas da instituição. Em relação ao educador social, a quantidade exigida é um profissional para até 10 usuários por turno (BRASIL, 2009). Os educadores sociais de instituições de acolhimento para crianças e adolescentes exercem o papel de cuidado, seja em relação a alimentação, higiene, fortalecimento da autoestima, proteção, organização do ambiente, acompanhamento em serviços de saúde, escolas, além de apoio na preparação do acolhido para o desligamento da instituição (BRASIL, 2009).

Por serem considerados como promotores de desenvolvimento saudável, resiliência e bem-estar na vida dos acolhidos (BERSCH; YUNES; GARCIA, 2018), estudos indicam características associadas ao papel do educador que podem constituir fator de proteção no curso do desenvolvimento dos adolescentes como o apoio emocional (MENDES; KAPPLER, 2018), suporte afetivo e instrumental (SIQUEIRA; DELL'AGLIO, 2006). Além da necessidade de que esses profissionais tenham clareza quanto a sua função (BRASIL, 2009), suporte psicológico (ROMERO et al., 2016), capacitação adequada (AVOGLIA; SILVA; MATTOS, 2012; CAVALCANTE; CORRÊA, 2012; PENNA; CARINHANHA; LEITE, 2009), práticas educativas, interações positivas (MARZOL; BONAFÉ; YUNES, 2012; WENDT, DELL'AGLIO, 2018) e um repertório de habilidades sociais educativas capazes de produzir ou gerar mudanças positivas no desenvolvimento socioemocional dos adolescentes (GUERRA; 
DEL PRETTE, 2018). Destaca-se a necessidade de que suas práticas sejam baseadas no diálogo e reflexão crítica (WENDT; DELL'AGLIO, 2018), sem recorrer a meios violentos ou punitivos (AVOGLIA; DA SILVA; REPPOLD, 2012), com reflexões sobre possibilidades em administrar os casos considerados difíceis diante das situações de violência e injustiça vividas pelos adolescentes (PENNA; CARINHANHA; LEITE, 2009).

Não obstante, os educadores enfrentam desafios frente às demandas da instituição que merecem atenção, tais como o despreparo da equipe, hostilidade, alto índice de criança por educador, práticas coercitivas, falta de planejamento de atividades (SIQUEIRA; DELL'AGLIO, 2007). Bem como, conflitos, pouco apoio administrativo, crenças e atitudes sobre crianças institucionalizadas e seus pais biológicos (VASHCHENKO; EASTERBROOKS; MILLER, 2010), agressão verbal, ameaças de privação e dificuldades em praticar a autoridade de forma adequada e afetiva (BATISTA; SILVA; REPPOLD, 2010). Sobre as práticas educativas mais saudáveis, salienta-se a importância dos educadores em criar estratégias indutivas que valorizem o diálogo, valorização de forças pessoais e méritos. Além do afeto, comunicação clara, estímulo de posturas mais ativas e a construção de emoções positivas, estimulando os acolhidos em suas potencialidades para o desenvolvimento da capacidade de refletir e dialogar (WENDT; DELL'AGLIO, 2018).

Levar em consideração as caraterísticas dos educadores que são promotoras de desenvolvimento e as que precisam de atenção, poderão fornecer indicadores para a elaboração de políticas de intervenção preventivas para esses profissionais, contribuindo para a prevenção e promoção de saúde mental e defesa dos direitos humanos dos adolescentes. Do ponto de vista teórico e político, é possível concluir a escassez de pesquisas que investigam o perfil e os aspectos do trabalho dos educadores em instituições de adolescentes (CAVALCANTE; CORRÊA, 2012), o que pode ser preocupante, visto a relevância do tema para os cuidados dos acolhidos.

O afastamento do acolhido de seus familiares durante o tempo de permanência na instituição pode gerar uma aproximação com o educador e o desenvolvimento de mecanismos de proteção para lidarem com essa situação. Desse modo, adolescentes que se encontram 


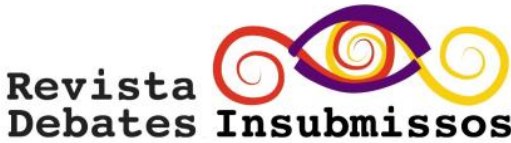

acolhidos em instituições ou em casas-lares podem encontrar nos educadores um apoio satisfatório nesses ambientes (ABAID; DELL'AGLIO, 2014). Percebe-se a potencialidade dos educadores sociais em favorecerem o desenvolvimento socioemocional dos adolescentes em acolhimento (BRASIL, 2009).

Estudos evidenciam a necessidade de compreender as percepções dos educadores sociais quanto a sua função e vínculos com os adolescentes, pois a institucionalização pode ser a principal fonte de apoio social e afetivo de jovens acolhidos (WENDT; DELL'AGLIO, 2018), Assim, é preciso adequar as práticas dos profissionais da instituição para proporcionar o favorecimento da autoestima, autoeficácia e de perspectivas positivas de cuidado e educação, ou seja, de fatores que podem contribuir para que o jovem acredite em si mesmo e na sua capacidade de sucesso. Essas práticas poderão favorecer os aspectos saudáveis, promovendo a autoestima e independência dos adolescentes acolhidos (WENDT; DELL'AGLIO, 2018). Portanto, o presente estudo, tem como objetivo investigar, por meio da técnica de grupo focal, as percepções dos educadores sociais sobre suas condições de trabalho na instituição de acolhimento e suas relações com os adolescentes.

\section{METODOLOGIA}

Trata-se de um estudo descritivo, com amostra selecionada por conveniência e abordagem qualitativa que investigou, por meio de grupos focais, as percepções dos educadores sociais sobre suas condições de trabalho na instituição de acolhimento e suas relações com os adolescentes. A presente pesquisa procurou por meio de seus instrumentos e procedimentos, assegurar a integridade física e moral dos participantes, abrangendo os aspectos éticos considerados essenciais em pesquisas com seres humanos pela Resolução 466/2012 do Conselho Nacional de Saúde. O projeto foi aprovado no Comitê de Ética em Pesquisa. Todos os participantes assinaram um Termo de Consentimento Livre e Esclarecido, no qual todas essas informações estavam descritas declarando que concordavam em participar da pesquisa.

\subsection{Participantes}




\section{Revista \\ Debates Insubmissos}

Foram realizados quatro grupos focais com a participação de 17 educadores de três instituições públicas de acolhimento da cidade do Rio de Janeiro. Destes, 13 eram homens (76,47\%), com idades entre 27 e 71 anos (M=45,76 anos; $\mathrm{DP}=12,51)$. Como critério de inclusão foi estabelecido o tempo de trabalho na instituição superior a um mês, supondo que esse seria um tempo mínimo para adaptação e conhecimento da rotina na instituição. Em relação ao estado civil, oito eram casados $(47,05 \%)$, cinco eram solteiros $(29,42 \%)$ e quatro $(23,52 \%)$ eram divorciados, viúvos, com companheiros ou outro. Sobre a escolaridade do educador social, a maior parte $(n=13,76,47 \%)$ possuía ensino médio completo. Em relação ao tempo de trabalho, a maioria $(\mathrm{n}=8,47,05 \%)$ atuavam há mais de cinco anos, seis $(35,29 \%)$ há dois anos a quatro anos e seis meses e três $(17,64 \%)$ há menos de dois anos e seis meses.

\subsection{Instrumentos}

Questionário de Caracterização dos Educadores Sociais. Instrumento elaborado para este estudo com intuito de investigar as características sociodemográficas dos educadores, tais como nome, sexo, idade, naturalidade, escolaridade, estado civil, tempo de trabalho na instituição e função na instituição.

Questionário de Classificação Socioeconômica. Questionário desenvolvido pela Associação Brasileira de Empresas de Pesquisa (ABEP, 2018) que tem por objetivo realizar um levantamento das condições, bens de consumo e orçamento das famílias brasileiras.

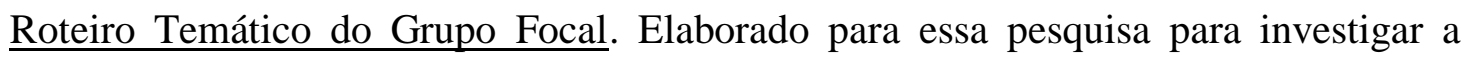
percepção dos educadores sociais quanto ao trabalho na instituição de acolhimento, suas práticas educativas e a relação dos educadores sociais com os adolescentes. Contém perguntas abertas norteadoras que buscaram promover a reflexão e a discussão entre os educadores sociais sobre os temas: trabalho como educador social (ex.: Qual a importância do emprego nessa instituição para a vida de vocês? Por quê?; Vocês se sentem apoiados pelos outros funcionários e equipe técnica? Por quê? De que forma?; Como você lida com as pressões e cobranças do diaa-dia da instituição?); adolescentes (ex.: O que é adolescência para você?; O que vocês acham que acontece quando os adolescentes são desligados da instituição ou completam 18 anos?); 
práticas educativas dos educadores sociais (ex.: Vocês acham que os educadores sociais influenciam o desenvolvimento socioemocional dos adolescentes? Como?; Como você expressa afeto e sentimentos positivos aos adolescentes?; Quais são as maiores dificuldades no relacionamento entre vocês e os adolescentes?).

\subsection{Procedimentos}

As instituições localizavam-se na região oeste e centro no Estado do Rio de Janeiro e foram selecionadas por serem de médio porte e atendimento integral, o que facilitaria a coleta de dados com um número maior de educadores sociais e que tivessem contato mais frequente com os adolescentes. Os participantes da pesquisa pertenciam a três instituições públicas de acolhimento com a capacidade de acolhimento de até 20 adolescentes do sexo masculino e que no momento da pesquisa estavam acima de $80 \%$ para capacidade máxima de lotação. Para a realização dos grupos focais, foram utilizadas sala da própria instituição, como bibliotecas e refeitórios. Em relação aos educadores sociais, o número de profissionais variou entre três e nove em cada instituição.

Os dados foram coletados entre agosto e novembro de 2019. Primeiramente o contato via telefone celular foi realizado com a coordenadora da instituição 1 para o convite aos educadores sociais para a participação do grupo focal. Como critério de inclusão foram convidados todos os educadores sociais que estariam no dia da realização do grupo na instituição (n=9) e exclusão aqueles que estavam ausentes do trabalho ou separados temporariamente por qualquer motivo. Estiveram presentes cinco educadores no primeiro grupo focal, os demais estavam realizando atividades externas. Após, considerando a ausência de quatro educadores sociais, foi estabelecido com a coordenadora da instituição 1 a realização do segundo grupo focal, levando em consideração a escala de trabalho dos outros quatro participantes que não estavam no primeiro grupo.

Outras duas instituições foram convidadas para participar da pesquisa. Para a seleção dessas instituições foi utilizado como critério de inclusão o número de educadores contratados na instituição para poder ter um número suficiente para a realização do grupo focal que, segundo 


\section{Debates Insubmissos}

Revista

BACKES et al. (2011), varia de 6 a 8 participantes. Um terceiro grupo focal foi realizado na instituição 2. Por fim, um quarto grupo foi realizado na instituição 3. Tanto para a instituição 2 quanto para a 3, a pesquisadora entrou em contato via telefone celular com as coordenadoras das instituições para realizar o convite aos educadores. $\mathrm{O}$ convite foi aceito e o grupos focais foram realizados. O tempo médio dos grupos foram de duas horas e foram realizados na parte da manhã ou tarde, de acordo com a disponibilidade da instituição.

Foi realizado quatro grupos focais seguindo os mesmos procedimentos de coleta de dados em três instituições (1, 2 e 3), sendo que na instituição 1 foi realizado dois grupos focais. Realizados de acordo com a proposta detalhada no Roteiro Temático do Grupo Focal, com o intuito de compreender os significados de ser e estar educador social e coletar informações sobre os seguintes temas: 1. Trabalho como educador social; 2. Percepção dos educadores sociais sobre adolescências e adolescentes; 3. Compreender as práticas educativas dos educadores sociais. $\mathrm{O}$ encontro foi organizado em três etapas, primeira introdução, a segunda a realização da proposta do encontro e a terceira etapa a finalização. Na parte introdutória do encontro, os educadores foram recebidos em uma sala disponibilizada pela instituição. Foi realizado um breve rapport com os educadores em grupo, com o intuito de gerar um ambiente favorável, apresentar as facilitadoras, explicar os objetivos da pesquisa e das atividades realizadas, dar instruções normativas sobre as regras do grupo, como desligar o celular, não falar ao mesmo tempo, evitar discussões paralelas, sigilo das informações e uso do gravador de voz. Na sequência, foi distribuído etiquetas adesivas para que os educadores escrevessem um nome fictício ou apelido que serviria como referência para a identificação dos mesmos na pesquisa. Foi assegurado ao grupo que o interesse do estudo seria apenas as suas opiniões, não havendo respostas certas ou erradas, sendo confidenciais e solicitado a assinatura do Termo de Consentimento Livre Esclarecido. A pesquisadora informava a disponibilidade para explicar possíveis dúvidas.

Na sequência foi realizado uma dinâmica da "Caixa de Fósforo" (baseado em Gromack, 2003) para levantar as expectativas do grupo sobre o encontro, onde solicitou-se que o educador pegasse um fósforo, depois acendesse e enquanto o fósforo queimava falasse brevemente sobre 


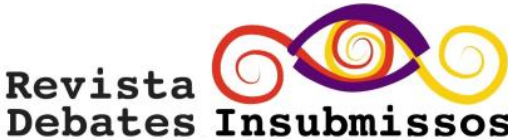

o que é ser educador social para ele. Em seguida, iniciou-se a segunda etapa do encontro para compreender as percepções dos educadores sobre o trabalho na instituição, adolescências e sobre o futuro dos adolescentes. Três cartazes foram confeccionados em cartolina branca com fotos representando diferentes contextos, exemplificando o dia a dia de uma instituição. Cada cartaz foi apresentado e a facilitadora realizava as perguntas adaptadas para esse estudo referentes ao tema de cada cartaz (BERSCH et al., 2019; DONADUZZI et al., 2015; GROMACK, 2003). Após esse momento, iniciou-se a terceira etapa do encontro com a finalização e fechamento do grupo.

\section{ANÁLISE DE DADOS}

O grupo focal é uma técnica utilizada na coleta de dados qualitativos nas áreas da antropologia, ciências sociais, mercadologia e educação em saúde, que ocorre a partir da interação em grupo. Trata-se de uma entrevista em grupo que permite aos participantes explorarem seus pontos de vista de um determinado fenômeno social, em seu próprio vocabulário, promovendo uma ampla problematização e troca de experiência sobre um tema ou foco específico (BACKES et al., 2011). Nóbrega, Andrade e Melo (2016) afirmam que o grupo focal é uma técnica de produção de dados para o acesso a informações por meio de uma conversação mais espontânea possível. No grupo focal o pesquisador atua como facilitador do processo de discussão e os participantes conversam sobre um tópico de discussão, expondo suas opiniões no grupo e assumindo seus posicionamentos, que podem ser colocados em uma posição de conflito com outros ou não (NÓBREGA; ANDRADE; MELO, 2016).

Para o planejamento do grupo focal foram estabelecidos os seguintes critérios e etapas de acordo com Silva Júnior, Silva e Mesquita (2014): (1) determinação do propósito do grupo focal; (2) recrutamento e seleção dos participantes; (3) determinação da quantidade de grupos focais a serem realizados; (4) elaboração do roteiro de entrevista coletiva; (5) preparação do facilitador e cofacilitador; (6) definição e preparação do local de realização dos encontros. 
A análise do corpus se deu a partir da realização da análise temática por meio de um estudo descritivo para identificar, analisar e categorizar os temas comuns emergentes das respostas dos educadores (BRAUN; CLARKE, 2006; GATO et al., 2020). Primeiro as falas dos participantes obtidas no grupo focal foram gravadas, transcritas e digitalizadas de forma manual pela pesquisadora em arquivos MS Word® totalizando quatro transcrições. Foi realizada uma leitura cuidadosa das transcrições de cada grupo e das respostas dos participantes, que passou por revisão ortográfica. Em seguida um esboço preliminar foi criado em um arquivo MS Word ${ }^{\circledR}$ onde todos os arquivos foram unificados. A partir desse arquivo, foram identificados e selecionados por cores três categorias: (1) Trabalho do Educador Social (cor cinza); (2) Adolescências (cor amarela); (3) Práticas de Sociabilização Educativas (cor azul). Em seguida, a pesquisadora realizou uma leitura sistemática para identificar as principais subcategorias, com exemplos de falas, em um arquivo em formato MS Excell@ com o número de frequências de ocorrências. Após, dois juízes realizaram uma revisão das categorias e subcategorias para observar padrões coerentes para controle de qualidade para validar a análise.

\subsection{Resultados e discussão}

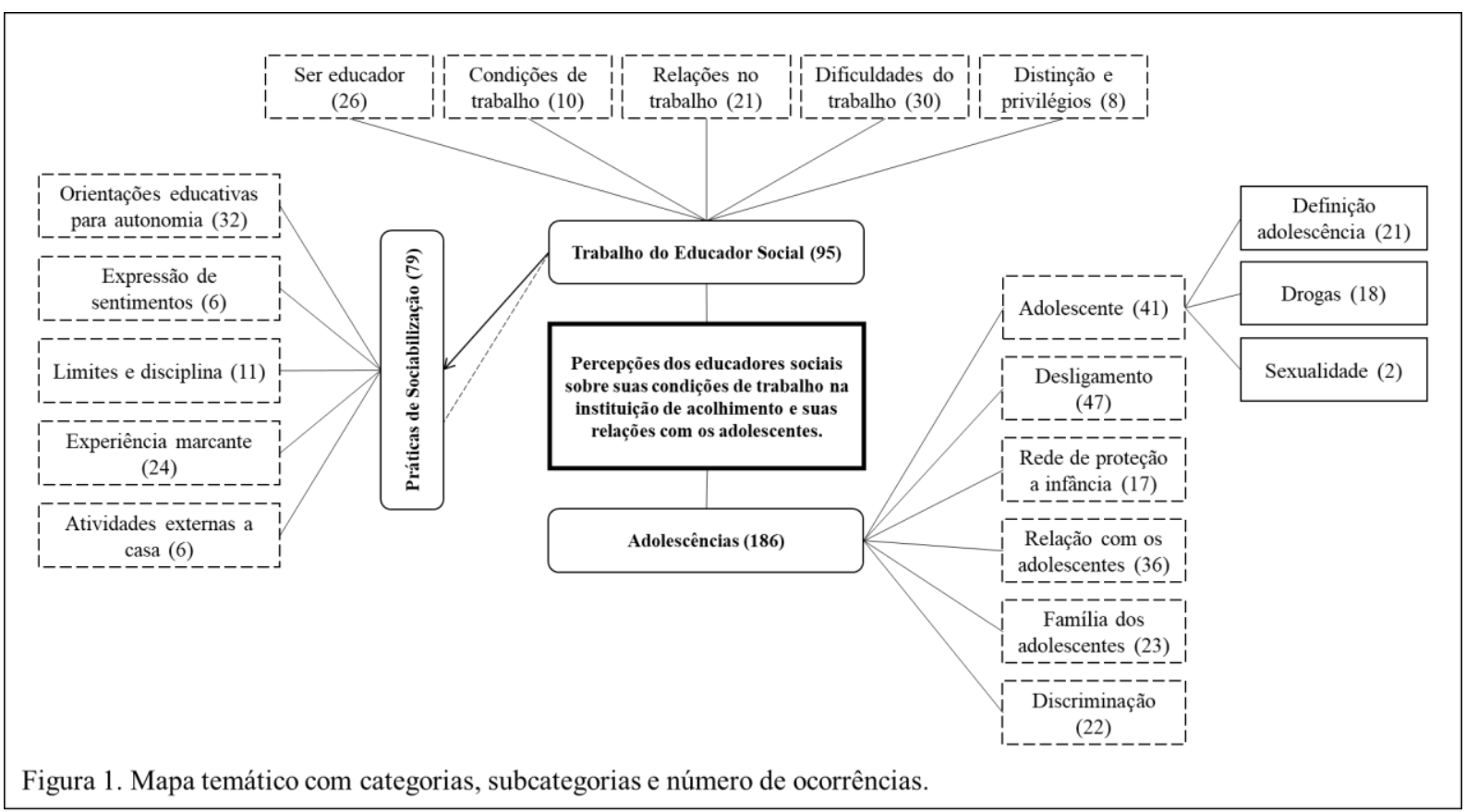

REVISTA DEBATES INSUBMISSOS, Caruaru, PE. Brasil, Ano 4, v.4, no 14, Edição Especial. 2021. ISSN: 2595-2803 Endereço: https://periodicos.ufpe.br/revistas/debatesinsubmissos/ 


\section{Revista \\ Debates Insubmissos}

A Figura 1 apresenta o mapa temático, contendo as categorias, subcategorias e as frequências de ocorrência encontrados no grupo focal com os educadores. Foi possível identificar três temas abrangentes: "Adolescências" $(n=186)$, que diz respeito a forma como os educadores compreendem essa fase da vida e sobre os adolescentes da instituição de acolhimento; "Trabalho do educador social" $(\mathrm{n}=95)$, que refere-se as condições de trabalho, dificuldades e formação para executar as atividades que são propostas na instituição; "Práticas de sociabilização" ( $\mathrm{n}=79)$, que aborda as orientações educativas e interações entre os educadores e adolescentes em acolhimento.

A seguir serão descritas, analisadas e discutidas cada uma das categorias. Para a descrição das citações de cada educador, será utilizado nomes fictícios escolhidos pelos próprios participantes da pesquisa.

$\mathrm{Na}$ categoria adolescências os educadores relataram principalmente informações sobre o processo de desligamento da instituição, as ações e percepção do educador sobre o processo de egresso, quando os adolescentes completam a maioridade, o futuro dos adolescentes e quais ações são realizadas na instituição para o retorno para família de origem

Porque eles já chegam numa idade que é uma corrida contra o tempo, então a gente
tenta né... encaixar na cabeça deles que chegou a hora né... e aí quando chega aos 17
e meio 18 , eles começam a correr pra fazer isso, pra fazer aquilo... o tempo é cruel, o
tempo passa e é como um ponto ligeiro ele vai e não volta mais. (RENATO, 54 anos)

Os resultados indicaram as preocupações dos educadores no decurso do desligamento e as dificuldades que se estabelecem nesse processo. $\mathrm{O}$ achado da pesquisa é semelhante ao identificado por Cassarino-Perez, Montserrat e Sarriera (2020) em relação aos cuidadores e a angústia por se sentirem desamparados no processo obrigatório de desligamento aos 18 anos dos adolescentes da instituição, além da quebra do vínculo e descontinuidade dos trabalhos devido às mudanças de equipe. Nesse sentido, os educadores necessitam de apoio tanto para a preparação das crianças ou adolescentes para o desligamento, como também ser orientado e supervisionado por um profissional de nível superior conforme estabelece a legislação (BRASIL, 1990; BRASIL, 2009). Dessa forma, a equipe técnica da instituição precisa estar atenta sobre os procedimentos capazes de gerar condições favoráveis à reinserção familiar, o 
que poderá auxiliar na redução das preocupações dos acolhidos com as perspectivas de eventos futuros.

A segunda subcategoria mais evidente foi adolescente com questões sobre a definição de adolescência, o que é ser adolescente para o educador, forma como os adolescentes se comportam na atualidade e na instituição, uso de drogas, abuso de substâncias, vícios, dependência, sexualidade, questões de gênero: Safira (48 anos) "Tem muita coisa que eles não sabem e não entendem. Uma geração que tá por fora"; Bolinha (51 anos): "Porque a gente convivia com esses adolescentes assim, é... cheio de vício". Esses achados corroboram os encontrados por Bersch, Yunes e Garcia (2020), que identificaram os termos que apresentam maior atribuição para as características das crianças e adolescentes com aspectos pejorativos, espectros negativos, tais como revoltado, arredio, sem limites, agressivo, questionador, teimoso, carente, chato, introvertido e desesperançoso (BERSCH; YUNES; GARCIA, 2020).

A percepção negativa sobre os adolescentes acolhidos vinda dos profissionais que prestam o cuidado podem influenciar na perspectiva que os adolescentes possuem sobre si mesmo e seu futuro. Faz-se necessário criar estratégias de reflexão e compreensão da representação do educador sobre o que é ser adolescente atualmente, pois as mudanças ocorridas nesta fase da vida envolvem outros fatores como as mudanças físicas, maturidade sexual, alterações cognitivas, emocionais e psicossociais, contemplando aspectos políticos, econômicos, ideológicos, grupos etários, da colocação do sujeito na família e de sua construção social (PAPALIA; FEUDMAN, 2013). Destaca-se a necessidade de ampliar a concepção da adolescência para educadores sociais para evitar relações estereotipadas, preconceituosas e comportamentos violentos com os jovens.

A terceira subcategoria foi a relação com os adolescentes que trata sobre o estabelecimento e preocupações sobre vínculos adolescente/educador. Tita (65 anos) "Eles aqui são muito grudados com a gente (...) eu viro vó, chamo atenção". Gui (38 anos) "Eles são muito achegados, eles têm muito referência com educadores". Piloto (37 anos) “A gente acaba criando um vínculo em algumas situações”. Para Delgado e Gersão (2018), o estabelecimento de relacionamento afetivo em instituições de acolhimento é dificultado porque os profissionais 
tentam manter um distanciamento interpessoal dos acolhidos para assegurar o seu desempenho profissional. Entretanto, estudos (CASTRO et al., 2016; CAVALCANTE; DA COSTA SILVA; MAGALHAES, 2010; GUIMARAES; NETO, 2015; RODARTE et al., 2015; VIEIRA; COUTINHO, 2019,) corroboram os achados nesta pesquisa, que indicam que a presença de vínculos afetivos com pessoas do abrigo e com o ambiente social externo e a interação positiva entre educadores e adolescentes são considerados fatores de proteção para um desenvolvimento saudável.

Em seguida a subcategoria família dos adolescentes relaciona-se com a percepção do educador referente à estrutura familiar dos adolescentes em acolhimento. Do Lins (28 anos) “Às vezes o adolescente vem pra cá e não sabem nem o que que é isso: família. É... meio estranho. Tu pegas uma imagem de uma família feliz: pai, mãe, irmãos, filhos e aqui as vezes tu vês um garoto que odeia a mãe, que odeia o pai e não quer que chega nem perto". Vieira e Coutinho (2019) afirmam que para os adolescentes em acolhimento, a ideia de família está diretamente ligada à composição do grupo (mãe, pai, irmãos, tia e vó) e de suas funções (afeto, cuidado, carinho, criação, sustento, entre outros) e que o laço consanguíneo é apenas uma característica do grupo familiar e não é determinante do mesmo.

Entretanto, Silva e Barros (2018) afirmam que uma das características marcantes do acolhimento institucional brasileiro é a concepção de incapacidade de cuidados de famílias de baixa renda em tutelarem suas crianças e adolescentes, atribuindo ao Estado a responsabilidade e intervenção neste grupo social. Vasconcelos, Yunes e Garcia (2009) perceberam que os educadores sociais possuíam percepções negativas sobre a família de origem, que estes não acreditavam no restabelecimento dos laços familiares, desconfiança acerca da relação entre mãe e filho, atribuição à situação de pobreza como causa da impossibilidade de retorno da criança à família de origem. Com os dados encontrados, foi possível perceber a necessidade de instrumentalizar os educadores de modo a questionar as suas perspectivas sobre as famílias dos acolhidos, evitando o estabelecimento de uma relação com interações pautadas em desconfiança, o que dificulta e prorroga o retorno do acolhido ao ambiente familiar. 


\section{Revista \\ Debates Insubmissos}

Em relação a discriminação foi encontrado as percepções e situações de discriminação, identificação por ser de uma instituição, os adolescentes e uso de uniforme pelos educadores. Ninico (31 anos) "Pra eles é uma vergonha estar no abrigo".

No passeio, se ele te identifica como família né, por que você vai estar de uniforme? Por que você vai estar com o crachá? É mais fácil: 'Não, o meu tio, o meu primo né'. Porque que eu vou parar na porta da escola num carro né, com touca, adesivo? Então, acho que a gente acaba fazendo uma construção pra... de... autoajuda né. De autoajuda pra eles poderem se sentir melhor. Não sentir discriminado pela sociedade né. (RENATO, 54 anos).

A percepção discriminatória de quem são os acolhidos pode influenciar no desenvolvimento e socialização dos adolescentes com sua família, comunidade e funcionários da instituição (CRUZ; PEDROSO; COSTA, 2018). Dessa forma, os achados deste estudo vão ao encontro da pesquisa de Patias, Siqueira e Dell'Aglio (2017) que realizaram uma reflexão teórica acerca das imagens sociais de crianças e adolescentes em acolhimento institucional e suas famílias. As autoras afirmaram que as imagens sociais dos acolhidos são compartilhadas por boa parte da sociedade e acabam por influenciar práticas em torno desses grupos sociais. Essas imagens foram construídas histórica e socialmente, nem sempre são condizentes com a realidade e hoje fazem parte do imaginário social. Destaca-se os prejuízos das imagens sociais negativas de adolescentes por terem sofrido maus-tratos, terem sido negligenciados por seus progenitores ou por pertencerem a famílias com dificuldades sociais ou psicossociais. Assim, é importante realizar intervenções com educadores sociais com o objetivo de modificação de crenças e imagens sociais, tendo em vista que diretamente estão envolvidos nos atendimentos desses sujeitos, o que pode refletir em suas práticas profissionais.

Por fim a subcategoria rede de proteção à infância aborda sobre políticas públicas, sociedade, polícia, atividades dos adolescentes no período que estão na instituição, cursos profissionalizantes, estágio, presentes que os adolescentes ganham para exercerem uma profissão.

Porque a política que a gente está vivendo hoje em dia tá realmente muito difícil pra quem mora em comunidade, pra quem realmente precisa de ajuda do governo, tá tendo esse suporte que a gente esperava ter, tá tendo esse... massacre, massacre é até uma palavra forte. (...) Os órgãos responsáveis podem fazer isso, tem condições de fazer isso e não quer. E é complicado, é realmente difícil. (LINZ, 28 anos). 


\section{Revista \\ Debates Insubmissos}

A importância de instituir políticas públicas para a garantia de direitos que contemplem as necessidades de crianças e adolescentes em acolhimento institucional também foi encontrada em outros estudos (BRASIL 2009; CALCING; BENETTI, 2014; SILVA; BARROS, 2018; FONSECA et al., 2013). Como as principais vulnerabilidades que acometem as crianças e os adolescentes em acolhimento envolvem fatores de risco (FONSECA et al., 2013), neste contexto, há necessidade de implantação de políticas públicas articuladas e sólidas, que perpassem os diversos aspectos da qualidade de vida, como a educação, moradia, saneamento básico, saúde, entre outros para o enfrentamento dos riscos nessa etapa da vida.

$\mathrm{Na}$ categoria trabalho do educador social os relatos mais frequentes dos profissionais foram sobre as dificuldades do trabalho que corresponde as dificuldades relatadas para execução das tarefas, falta de acesso às informações sobre os adolescentes, desvalorização da profissão por parte dos governantes, tensão entre equipe técnica.

\footnotetext{
Mas o adolescente chega e relata muita coisa. Só que é aquilo, a gente não pode se basear pelo que o adolescente fala. Baseado nisso, a gente até procura ter informação porque, não tem como se falar, se fazer alguma coisa, sem a gente ter uma afirmação correta. Vou fazer o que? Onde é que eu vou intensificar o meu trabalho se eu não sei onde é que é deficiente. Então essa informação ela nos é reclusa, até por um sigilo técnico. (PILOTO, 37 anos).
}

Nota-se que a falta de informação sobre a vida pregressa dos adolescentes pode trazer para os educadores sociais sensações de não saber como agir e dificuldades em realizar o trabalho. Tais evidências são corroboradas por Penna, Carinhanha e Leite (2009) que salientam que o educador pode apresentar dificuldades por não se sentir capacitado para administrar os casos considerados difíceis diante das situações de violência e injustiça vividas pelas adolescentes. Assim, é necessário capacitar os profissionais com o intuito de resgatar e sensibilizar os educadores para a relevância das ações dialógicas junto aos adolescentes, o aumento da atualização sobre o tema violência, no sentido de potencializar sua habilidade como educadores, como facilitadores do processo de ressignificação do valor da vida, do fortalecimento da autoestima das jovens, o que justifica a relevância do desenvolvimento das habilidades sociais dos educadores. Diante do exposto, ressalta-se a necessidade de fundamentar intervenções preventivas, com estratégias de qualificação dos educadores para 


\section{Revista \\ Debates Insubmissos}

aprimoramento contínuo, mostrando o que é exigido tecnicamente para o cargo, a realidade da instituição, suporte psicológico e psiquiátrico, evitando o adoecimento desses sujeitos.

Sobre a subcategoria ser educador que refere à percepção do educador sobre sua profissão, como deve exercê-la, tarefas realizadas na instituição, diferenças encontradas antes e depois de se tornar educador.

Ser educador é uma oportunidade que a gente tem de ensinar e aprender muito com os adolescentes [...] É vivência, mostrar a vivência, mostrar o que você já passou, o que você pode passar e o que eles já passaram. É uma troca de ideias. Oportunidade que a gente tem de crescer, de poder realizar os sonhos deles, os nossos. (DO LINS, 28 anos).

Esse achado se relaciona com a percepção do papel do educador quanto sua função (BRASIL, 2009) e a necessidade de que suas práticas sejam educativas e baseadas em interações positivas (MARZOL; BONAFÉ; YUNES, 2012; WENDT; DELL'AGLIO, 2018). Aquele que cuida também precisa de cuidados, por isso a necessidade da formação continuada com encontros, troca, diálogos, reconhecimento do papel que ocupa, com um olhar reflexivo sobre o trabalho e conhecimento dos objetivos da instituição. Assim, condiz a criação de estratégias e políticas públicas que poderão instrumentalizar os educadores sobre a forma como lidam com os sofrimentos e mazelas decorrentes do convívio com crianças e adolescentes em risco social e pessoal.

Em relação a subcategoria relações no trabalho que diz respeito a percepções de apoio ao executar as tarefas, amizades, relação dos profissionais da instituição, da equipe técnica e como a família percebe sua profissão: França (71 anos) "É unido sim, às vezes tem alguma diversificação mais no geral é unido".

Às vezes o apoio vem dos próprios colegas, né. E às vezes não só a gente pede, como o próprio colega vê que a gente está numa situação meio constrangedora, o próprio colega avisa né: 'não é dessa forma, você tem que agir de outra forma' (...) E tem me ajudado muito. Você não vê, você pensa que tá ajudando, você só tá atrapalhando. (SAFIRA, 48 anos).

A interação estabelecida entre educadores e a equipe (BRASIL, 1990; CAVALCANTE et al., 2010; GUIMARÃES; NETO, 2015) é relevante pois, pode aumentar os conhecimentos dos educadores sobre quem é o acolhido, sua história de vida, a trajetória da família, o reconhecimento do sistema familiar atual, os padrões de interação, a presença de fatores de 
risco e proteção (CAVALCANTE; DA COSTA SILVA; MAGALHAES, 2010). A legislação indica o estabelecimento de reuniões trimestrais, para que cada acolhido tenha sua situação analisada pela equipe técnica da instituição e a cada seis meses com audiências junto do juiz, equipe técnica da vara da infância, equipe da própria instituição e demais colaboradores (BRASIL, 1990). Essas reuniões podem servir como instrumentos para que os educadores recebam o apoio necessário para executar sua função, reconhecimento de suas práticas e melhora de seu desempenho profissional.

Sobre a subcategoria condições de trabalho que diz respeito a infraestrutura da instituição, prédio, material, mobiliário, capacidade de acolhimento, folga, alimentação, formação para executar a função, cursos e capacitações.

\footnotetext{
Porque a grande questão é como lá era, a casa de acolhimento. Na época que eles falaram que já chegou a 26 (acolhidos) e a estrutura era mais precária do que nós temos hoje. A questão é que não existe um espaço criado para receber os adolescentes. A gente pega uma casa, igual casa de família, normal que adaptou para ser um abrigo de adolescentes. Um exemplo: um banheiro para 15 meninos. Não é uma estrutura adequada. Temos quartos legais, tem quatro quartos, tudo bem, mas é que ficam pegando casas para fazer de abrigo. $\mathrm{O}$ ideal seria ter um espaço criado para ser abrigo, uma estrutura para receber o adolescente. Porque isso também gera estresse nele e em nós. (COROÃO, 54 anos).
}

Para Proctor, Linley e Maltby (2009) atividades sociais, as condições ambientais e a moradia são fatores relevantes para a satisfação com a vida de jovens. Dessa forma, a infraestrutura de uma instituição de acolhimento deve ser levada em consideração para que a passagem do acolhido seja a menos traumática possível. Os achados da pesquisa contrariam o estabelecido pela normatização referente à infraestrutura da instituição de acolhimento, que estabelece que a instituição deve manter os aspectos semelhantes aos padrões arquitetônicos residenciais do bairro ao qual está inserida (BRASIL, 2009). Observa-se a necessidade de que as diretrizes estabelecidas pelo "Orientações Técnicas" sejam cumpridas na prática, como por exemplo, aspectos da infraestrutura e espaços mínimos sugeridos, como a quantidade de banheiros que deve possuir um lavatório, um vaso sanitário e um chuveiro para até seis acolhidos (BRASIL, 2009). O que poderá reduzir situações de estresse entre adolescentes e educadores sociais. 


\title{
Revista \\ Debates Insubmissos
}

Em relação à subcategoria distinção e privilégios que diz respeito à percepção dos educadores de que os adolescentes teriam privilégios por estarem em acolhimento, diferenças entre o tratamento dos adolescentes em acolhimento e o tratamento dos membros de sua própria família observa-se.

\begin{abstract}
E não só na questão da alimentação, na questão de lazer, né. Eles vão em lugares assim, que eu nunca levei a minha filha: Water Planet, cinema, parque, AquaRio, Maracanã. Teve jogos olímpicos e vários eventos. Então é isso que a gente tenta passar pra eles, pra eles valorizarem isso. De vez em quando eles recebem: vestimenta, bom estágio, curso profissionalizante e eles desperdiçam a oportunidade. (COROÃO, 54 anos).

Eu na minha casa não tenho essas cinco refeições por dia e eu sou um trabalhador. Não é que eu não queira fazer essas cinco refeições né, mas eles aqui fazem, meus filhos às vezes não fazem essas cinco refeições e eles não dão valor. (POKÉMON, 42 anos).
\end{abstract}

Segundo o Artigo $7^{\circ}$ do ECA é direito de toda criança e adolescente a proteção à vida, à saúde, o desenvolvimento sadio, harmonioso e condições dignas de existência (BRASIL, 1990). Os dados da pesquisa evidenciam as atividades e práticas institucionais que colaboram para que esse desenvolvimento sadio se estabeleça. Entretanto, foram encontrados níveis de comparação entre os adolescentes acolhidos e as experiências vividas pelos educadores e seus familiares. Cavalcante e Corrêa (2012) encontraram que as motivações por trabalhar em instituição de acolhimento estavam ligados a estabilidade no emprego, oportunidade de trabalhar com crianças, desemprego à época da contratação e incentivo de terceiros que apoiavam esse tipo de serviço. Ao se comparar a percepção das educadoras quanto ao trabalho realizado, observou-se contraste entre o perfil ideal de educador, sugerido nas normas e as condições reais de trabalho. Evidencia-se a necessidade de ampliar estudos que abordem as motivações dos educadores quanto ao trabalho, além de políticas públicas para que suas remunerações salariais e benefícios sejam suficientes para melhor qualidade de vida desses profissionais.

Por fim, na categoria práticas de sociabilização os relatos mais frequentes foram encontrados na subcategoria orientações educativas para autonomia referente a ações e orientações do educador para que os adolescentes desenvolvam o desejo de estudar, aumentar o autoconhecimento, demonstração e exemplos de vida, incentivo, ajudar, cooperar, auxílio nas tarefas da casa e da escola. 


\section{Revista \\ Debates Insubmissos}

Então tudo isso é passado, orientado, é construído com eles. Oh, lá fora vocês vão ter que caminhar com suas próprias pernas, então você tem que aprender a respeitar né. Aquele, bom dia, aquele boa tarde né. Então tudo isso você tem que aprender a construir aqui dentro. Para quando chegar lá fora, você não dá cabeçada e dizer que a sociedade não gosta de vocês. (RENATO, 54 anos).

Os relatos evidenciam a busca, por parte dos educadores, de desenvolverem o senso de autonomia e responsabilidade individual dos adolescentes, o que se assemelha com os dados observados por Wendt e Dell'Aglio (2018) que relatam que as práticas institucionais positivas de cuidado e educação podem favorecer a autonomia, autoestima e a autoeficácia. Além de aspectos saudáveis como as potencialidades, independência e qualidade de quem está sob acolhimento. Evidencia-se a necessidade de estabelecer práticas educativas na instituição, para que o jovem acredite em si mesmo e na sua capacidade de sucesso em seu desenvolvimento.

Em relação a subcategoria experiência marcante que aborda relatos de eventos ou situações com os adolescentes que foram memoráveis para os educadores em sua trajetória profissional.

Um garoto que chegou aqui bem debilitado, transtorno mental bem avançado, a gente achava que o garoto não ia ter mudança, não ia ter nada e a gente pode com ele trabalhar e ele foi evoluindo cada dia mais. No dia do aniversário de 18 anos dele a gente organizou de fazer uma festinha surpresa. Chamamos a mãe dele, o padrasto, a irmã. Chamou os garotos aqui do abrigo para poder bater parabéns para ele. Aí no dia, acabou de bater o parabéns e para quem vai ser o primeiro pedaço de bolo? Aí ele me olhou, aí eu olhei pra ele e falei 'não... tua mãe tá ai', ai ele 'meu primeiro pedaço de bolo? Vai pro meu pai o Do Lins'. Ele me deu um abraço, aí ele chorando, falei 'pô, não chora não, fica tranquilo' aí ele disse 'não vou mais te ver'. 'Vai me ver sim rapa, fica tranquilo' Aí depois ele deu pra cozinheira: 'para minha mãe Maria'. Depois que ele deu pra mãe (biológica) dele. Aí a gente vê, pô, a história da mãe dele, é uma pessoa show de bola e o garoto escolheu o cara que ele conheceu a três, quatro meses, uma mulher que ele conheceu três, quatro meses, tirando como pai como mãe. (DO LINS, 28 anos).

Essa categoria demonstra a influência das relações no desenvolvimento do adolescente, o que denota a importância de interações positiva dos acolhidos, com seus familiares, pares e educadores. Esse dado evidencia o estabelecimento de vínculo entre educador e adolescente. De acordo com a pesquisa de Castro et al. (2016), os educadores percebiam-se como um apoio importante para os acolhidos e que esse vínculo podia influenciar no tratamento afetuoso. Em relação aos educadores, essas interações podem ser promotoras de desenvolvimento durante todo o período de acolhimento, esse achado assemelha-se com os dados de Cruz, Pedroso e 


\section{Revista \\ Debates Insubmissos}

Costa (2018) que afirmam que a relação dos educadores com as crianças e adolescentes podem favorecer a aquisição de habilidades para lidarem com o período que se encontram na instituição e após saírem dela. Assim, nota-se a necessidade de espaços de discussão e reflexão sobre as experiências vivenciadas pelos educadores, como forma de elaborar suas emoções e expectativas diante o relacionamento com os acolhidos.

Sobre a subcategoria limites e disciplina que diz respeito a estabelecimento de regras, disciplina, respeito, castigo, foi possível destacar o relato do educador MJ (50 anos) "A gente procura dizer que aqui é a sua casa, é sua família. Então tem regras que você tem que aprender. Para quando chegar lá fora, executar tudo o que aprendeu aqui dentro" e Renato (54 anos) "Eles chegam aqui na porta e batem, perguntam se podem entrar, né da licença... Posso sair". Esse dado corrobora o encontrado por Castro et al. (2016) que afirmam que a relação entre acolhidos e educadores precisa ser estabelecida por meio da autoridade e limites, de forma afetuosa, onde os educadores são um apoio importante para os adolescentes. Evidencia-se a relevância de estabelecer contextos interativos educativos, limites e disciplina coerentes, interrompendo comportamentos indesejados, explicando consequências de comportamentos ou expressando verbalmente concordância, para o desenvolvimento saudável do acolhido.

Já a subcategoria atividades externas à casa aborda as relações estabelecidas e realizadas pelos educadores com os adolescentes fora da instituição. Destaca-se a fala do educador Negão (48 anos) "A gente acabou pegando afinidade. Porque levava ele para passear, levava ele para passar o Natal na minha casa". Para Cruz, Pedroso e Costa (2018) é importante que além dos cuidados técnicos, sejam ofertados o fortalecimento de vínculos com passeios e o brincar entre educadores e acolhidos. Esse dado favorece a compreensão de que fatores como, a qualidade do ambiente e das relações humanas são determinantes para promover o desenvolvimento de processos de resiliência dos acolhidos (CASTRO et al., 2016).

Por fim, a subcategoria expressão de sentimentos que aborda as ações do educador em identificação/expressão de sentimentos dos adolescentes.

Eles vêm e procuram um apoio, um colo, um abraço e eles querem ter isso. Eles procuram. A gente não faz isso porque eles gostam. Se a gente não fosse se preocupar, a gente não estaria nem aqui. Porque isso também é o trabalho né, você perceber 


\section{Revista \\ Debates Insubmissos}

quando eles estão tristes, quando eles não estão comendo legal, quando eles estão assim. A gente percebe a mudança de humor dos garotos e quando a gente se interessa por eles, eles gostam. Poxa estou sendo notado, porque a vida deles é a rejeição né. (COROÃO, 54 anos).

Esse dado sugere que os educadores compreendem que o reconhecimento emocional faz parte do trabalho, como também a necessidade de corresponder positivamente diante uma manifestação emocional dos adolescentes. O que condiz com a pesquisa de Guerra e Del Prette (2018) que descreveram o item que teve maior frequência de ocorrência entre os educadores, a expressão de sentimento positivo, onde os educadores apresentaram repertório elaborado em habilidades sociais educativas e a habilidade que teve maior ocorrência na autoavaliação foi "percebo quando a criança está feliz e satisfeita". Esse dado evidencia a importância do reconhecimento do educador sobre o sentimento dos adolescentes, como forma de contribuição para o desenvolvimento socioemocional do acolhido. Verifica-se a necessidade de estimular práticas educativas mais saudáveis (WENDT; DELL'AGLIO, 2018) para os educadores, com estratégias indutivas que valorizem o diálogo, valorização de forças pessoais, o afeto, comunicação clara e construção de emoções positivas, estimulando os acolhidos em suas potencialidades.

\section{CONCLUSÕES}

O presente estudo contribuiu para a compreensão das percepções dos educadores sociais sobre suas condições de trabalho na instituição de acolhimento e suas relações com os adolescentes, o que tem sido pouco estudado nas pesquisas brasileiras. A estratégia do grupo focal permitiu que os educadores apresentassem suas percepções sobre adolescência, que envolvia preocupações com o desligamento dos adolescentes da instituição, a discriminação dos jovens e uma imagem social negativa dos acolhidos e seus familiares. Em relação ao trabalho, dificuldades foram relatadas sobre o dia a dia na instituição, as condições para o desempenho da função e a comparação com as suas vivências e dos adolescentes. Práticas de sociabilização e proteção social foram relatadas, objetivando a autonomia dos acolhidos, como também limites e disciplina. Observou-se que foram realizadas atividades fora da instituição, 


\section{Revista \\ Debates Insubmissos}

possibilidades de expressão de sentimentos e experiências que marcaram suas carreiras profissionais, com interações positivas e relações baseadas em vínculos afetuosos.

A presente pesquisa apresentou algumas limitações. Primeiro a amostra foi escolhida por conveniência e os dados coletados só ocorreram com educadores de instituições públicas. Segundo o número reduzido de participantes, devido a execução de trabalhos externos no dia dos encontros. Ressalta que mesmo com as limitações encontradas o estudo pôde identificar que o uso do grupo focal permitiu compreender as percepções dos educadores sociais frente aos acolhidos. Futuros estudos podem ser realizados em instituições públicas e particulares para saber se há diferenças entre sexo dos participantes e níveis socioeconômicos.

As informações do presente estudo evidenciaram a necessidade da criação de intervenções positivas para educadores sociais, que visem o respeito, a vulnerabilidade humana e a integridade dos acolhidos, instrumentalizando-os para serem promotores de desenvolvimento saudável, resiliência e bem-estar na vida de adolescentes em instituição de acolhimento. Tais intervenções podem facilitar uma atuação adequada dos profissionais que, possivelmente, ocasionaria em uma oferta de um melhor ambiente aos acolhidos, com uma escuta sensível e, ao mesmo tempo, transformadora. Para tal, é necessário ampliar os espaços de escuta para que os educadores reflitam sobre o trabalho desenvolvido com cada adolescente e as dificuldades encontradas em sua profissão para serem reconhecidos como figura de autoridade e construção de vínculo afetivo saudável. Além de uma capacitação inicial de qualidade, formação continuada e estudos de caso, possibilitando que as instituições de acolhimento sejam um espaço promotor do desenvolvimento socioemocional, com recursos pessoais para a sociabilidade dos acolhidos. Favorecendo futuros projetos, políticas públicas e práticas preventivas e de promoção da saúde, tanto para os acolhidos quanto para os educadores sociais que atuam nas instituições. 


\section{REFERÊNCIAS}

ABAID, Josiane Lieberknecht Wathier; DELL'AGLIO, Débora Dalbosco. Exposição a fatores de risco de adolescentes em acolhimento institucional no Sul do Brasil. Interação em Psicologia, v. 18, n. 1, 2014.

ABEP. ASSOCIAÇÃO BRASILEIRA DE EMPRESAS DE PESQUISA. Critério de classificação econômica Brasil. 2008.

ABREU, Samia; BARLETTA, Janaína Bianca; MURTA, Sheila Giardini. Prevenção e promoção em saúde mental: pressupostos teóricos e marcos conceituais. In: MURTA, Sheila Giardini; LEANDRO-FRANÇA, Cristineide; SANTOS, Karine Brito dos; POLEJACK, Larissa (Orgs). Prevenção e promoção em saúde mental: fundamentos, planejamento e estratégias de intervenção. Novo Hamburgo: Sinopsys, 2015. 54-74p., 864p.

ARPINI, Dorian Mônica. Repensando a perspectiva institucional e a intervenção em abrigos para crianças e adolescentes. Psicologia: Ciência e Profissão, v. 23, n. 1, p. 70-75, 2003.

AVOGLIA, Hilda Rosa Capelão; DA SILVA, Andreia Maria; DE MATTOS, Pammela Makarowits. Educador social: imagem e relações com crianças em situação de acolhimento institucional. Revista Subjetividades, v. 12, n. 1-2, p. 265-292, 2012

BACKES, Dirce Stein et al. O mundo da saúde, v. 35, n. 4, p. 438-442, 2011.

BATISTA, Giorgina Leni; DA SILVA, Patricia Santos; REPPOLD, Caroline Tozzi. Práticas educativas e estratégias de coping em crianças abrigadas. Aletheia, n. 33, 2010.

BERSCH et al. Programa de formação de educadores sociais na promoção da resiliência profissional. Rio Grande: EDGRAF, 2019.

BERSCH et al. Educador social promotor de boas práticas e resiliência em instituições de acolhimento. In: CAVALCANTE, Lília Iêda Chaves et al. (Orgs.) Acolhimento institucional de crianças e adolescentes: teorias e evidências científicas para boas práticas. Curitiba: Juruá, 2018. p. 253-266.

BERSCH, Ângela Adriane Schmidt; YUNES, Maria Angela Mattar; GARCIA, Narjara Mendes. Interlocuções da Educação Ambiental, da Abordagem Bioecológica de Desenvolvimento Humano e o conceito de resiliência profissional. REMEA-Revista Eletrônica do Mestrado em Educação Ambiental, v. 37, n. 4, p. 228-246, 2020.

BRASIL. Redefine a Política Nacional de Promoção da Saúde (PNPS). Portaria n ${ }^{\circ} 2.446$, de 11 $\begin{array}{lll}\text { de novembro } & \text { de } & 2014 .\end{array}$ https://bvsms.saude.gov.br/bvs/saudelegis/gm/2014/prt2446_11_11_2014.html 
BRASIL. Lei $\mathrm{n}^{\circ}$ 8.069, de 13 de julho de 1990. Dispõe sobre o Estatuto da Criança e do Adolescente e dá outras providências, 1990.

BRASIL. Orientações técnicas: serviços de acolhimento para crianças e adolescente. Conselho Nacional dos Direitos da Criança e do Adolescente. Conselho Nacional de Assistência Social, 2009.

BRAUN, Virginia; CLARKE, Victoria. Using thematic analysis in psychology. Qualitative research in psychology, v. 3, n. 2, p. 77-101, 2006.

BUFFA, Carolina Gobato; TEIXEIRA, Sueli Cristina de Pauli; ROSSETTI-FERREIRA, Maria Clotilde. Vivências de exclusão em crianças abrigadas. Psicologia: teoria e prática, v. 12, n. 2, p. 17-34, 2010.

CALCING, Jordana; BENETTI, Silvia Pereira da Cruz. Caracterização da saúde mental em crianças e adolescentes em acolhimento institucional. Psico, v. 45, n. 4, p. 559-567, 2014.

CASSARINO-PEREZ, Luciana; MONTSERRAT, Carme; SARRIERA, Jorge Castellá. Fatores Protetivos e de Risco na Transição entre o Acolhimento Institucional e a Vida Adulta. Estudos e Pesquisas em Psicologia, v. 20, n. 1, p. 142-167, 2020.

CASTRO, José Miguel Martín et al. Resilience paradigm's contributions to socio educational work. The case of the center Zabaloetxe for unaccompanied migrant children. Pedagogía Social. Revista Interuniversitaria, n. 28, p. 157-168, 2016.

CAVALCANTE, Lília Iêda Chaves; CORRÊA, Laiane Da Silva. Perfil e trajetória de educadores em instituição de acolhimento infantil. Cadernos de pesquisa, v. 42, n. 146, p. 494-517, 2012.

CAVALCANTE, Lília Iêda Chaves; DA COSTA SILVA, Simone Souza; MAGALHÃES, Celina Maria Colino. Institucionalização e reinserção familiar de crianças e adolescentes. Revista MalEstar e Subjetividade, v. 10, n. 4, p. 1147-1172, 2010.

CAVALCANTE, Lília Iêda Chaves; MAGALHÃES, Celina Maria Colino; PONTES, Fernando Augusto Ramos. Processos de saúde e doença entre crianças institucionalizadas: uma visão ecológica. Ciência \& Saúde Coletiva, v. 14, p. 615-625, 2009.

CNJ. Conselho Nacional de Justiça, 2011. Disponível em: https://paineisanalytics.cnj.jus.br/ single/?appid=ccd72056-8999-4434-b913-f74b5b5b31a2\&sheet=e78bd80b-d486-4c4e-ad8a7 36269930c6b\&lang=pt-BR\&opt=ctxmenu,currsel\&select=clearall, atualizada em 10/04/2021 às 10:00:46h.

CRUZ, Edson Junior da Silva; PEDROSO, Janari da Silva; COSTA, Amanda Cristina Ribeiro. Interações de crianças e adolescentes com adultos e grupo de pares: Relações promotoras do desenvolvimento. In: CAVALCANTE, Lília Iêda Chaves et al. (Orgs.) Acolhimento institucional 
de crianças e adolescentes: teorias e evidências científicas para boas práticas. Curitiba: Juruá, 2018. p. 147-159.

DELGADO, Paulo; GERSÃO, Eliana. O acolhimento de crianças e jovens no novo quadro legal. Novos discursos, novas práticas? Análise Social, v. 226, n. 53, p. 112-134, 2018.

DONADUZZI, Daiany Saldanha da Silveira et al. Grupo focal y análisis de contenido en investigación cualitativa. Index de enfermería, v. 24, n. 1-2, p. 71-75, 2015.

FONSECA, Franciele Fagundes et al. As vulnerabilidades na infância e adolescência e as políticas públicas brasileiras de intervenção. Revista Paulista de Pediatria, v. 31, n. 2, p. 258-264, 2013.

FURLAN, Vinicius; SOUZA, Telma Regina De Paula. Exclusão/inclusão social: políticas públicas de acolhimento institucional dirigidas à infância e juventude. Diálogo, n. 23, p. 35-48, 2013.

GATO, Jorge et al. "The Worst Part Was Coming Back Home and Feeling Like Crying": Experiences of Lesbian, Gay, Bisexual and Trans Students in Portuguese Schools. Frontiers in psychology, v. 10, p. 2936, 2020.

GONÇALVES, Ana Maria Pacheco Mendes Perdigão Costa; CAMARNEIRO, Ana Paula. Validação da Resilience Scale de Wagnild e Young em contexto de acolhimento residencial de adolescentes. Revista de Enfermagem Referência, v. 4, n. 17, p. 107-117, 2018.

GROMACK, Luiza. (Org.). Oficina de Ideias: manual de dinâmicas, 2003.

GUERRA, Lívia Lira; DEL PRETTE, Zilda Pereira. Habilidades sociais educativas de cuidadores de crianças institucionalizadas. Arquivos Brasileiros de Psicologia, v. 70, n. 3, p. 98-112, 2018.

GUIMARÃES, Cleusa da Piedade; NETO, Sebastião Benício da Costa. (2015). Suporte social como mediador de resiliência em adolescentes institucionalizados. Um estudo de caso. In: COIMBRA, Renata Maria; MORAIS, Normanda Araujo de (Orgs), A resiliência em questão. Perspectivas teóricas, pesquisa e intervenção. Porto Alegre: Artmed, 2015.

MACHADO, Evelcy Monteiro; MACHADO, Larissa Monteiro. Reflexões sobre a educação social e desafios à formação e ao trabalho do educador social no Brasil. In.: DELGADO, Paulo et al. (Eds.). Teorias \& Práticas: espaços de investigação, formação e ação. Escola Superior de Educação do Politécnico do Porto, 2014.

MACHADO, Vanessa Rombola. A atual política de acolhimento institucional à luz do estatuto da criança e do adolescente. Serviço Social em Revista, v. 13, n. 2, p. 143-169, 2011.

MARZOL, Rosinha Mattos; BONAFÉ, Larissa; YUNES, Maria Angela Mattar. As perspectivas de crianças e adolescentes em situação de acolhimento sobre os cuidadores protetores. Psico, v. 43, n. 3, 2012. 
MENDES, Deise Maria Leal Fernandes; KAPPLER, Stella Rabello. Afetividade e socialização da emoção no contexto de acolhimento institucional: os educadores sociais como agentes no desenvolvimento emocional infantil. In: CAVALCANTE, Lília Iêda Chaves et al. (Orgs.). Acolhimento institucional de crianças e adolescentes: teorias e evidências científicas para boas práticas. Curitiba: Juruá, 2018. p. 221-236.

NÓBREGA, Danielle Oliveira; ANDRADE, Erika dos Reis Gusmão; MELO, Elda Silva do Nascimento. Pesquisa com grupo focal: contribuições ao estudo das representações sociais. Psicologia \& Sociedade, v. 28, n. 3, p. 433-441, 2016.

PAPALIA, Diane E.; FELDMAN, Ruth Duskin. Desenvolvimento humano. Artmed editora, 2013.

PATIAS, Naiana Dapieve; SIQUEIRA, Aline Cardoso; DELL'AGLIO, Débora Dalbosco. Imagens sociais de crianças e adolescentes institucionalizados e suas famílias. Psicologia \& Sociedade, v. 29, 2017.

PENNA, Lucia Helena Garcia; CARINHANHA, Joana Iabrudi; LEITE, Ligia Costa. A prática educativa de profissionais cuidadores em abrigos: Enfrentando a violência vivida por mulheres adolescentes. Revista Latino-Americana de Enfermagem, v. 17, n. 6, 2009.

PROCTOR, Carmel L.; LINLEY, P. Alex; MALTBY, John. Youth life satisfaction: A review of the literature. Journal of happiness studies, v. 10, n. 5, p. 583-630, 2009.

RODARTE, Bárbara Cristina et al. Fatores de proteção sob o olhar de adolescentes vitimizados e institucionalizados. Revista de Enfermagem Referência, v. 4, n. 7, p. 73-80, 2015.

ROMERO, Daniel Luiz et al. Transtornos mentais comuns em educadores sociais. Jornal Brasileiro de Psiquiatria, v. 65, n. 4, p. 322-329, 2016.

SALINA-BRANDÃO, Alessandra; WILLIAMS, Lúcia Cavalcante de Albuquerque. O abrigo como fator de risco ou proteção: avaliação institucional e indicadores de qualidade. Psicologia: Reflexão e Crítica, v. 22, n. 3, p. 334-352, 2009.

SANTOS, Laís Katharina da Paixão dos; SANTANA Cláudia de Carvalho; SOUZA, Marta Vanessa Oliveira de. Ações para o fortalecimento da resiliência em adolescentes. Ciência \& Saúde Coletiva, 25(10):3933-3943, 2020.

SILVA JÚNIOR, Annor da; SILVA, Priscilla de Oliveira Martins da; MESQUITA, José Marcos Carvalho de. As dimensões teórica e metodológica do grupo focal no contexto da pesquisa qualitativa. In: SOUZA, Eloisio Moulin de (Org.) (2014). Metodologias e analíticas qualitativas em pesquisa organizacional [recurso eletrônico]: uma abordagem teórico-conceitual. Vitória: Editora da Universidade Federal do Espírito Santo EDUFES. 296. 
SILVA, Fabíola Helena Oliveira Brandão; BARROS, Rosana Maria Souza. Cantinho do recado: Desenvolvimento da linguagem e das habilidades sociais de crianças e adolescentes em acolhimento institucional. In: CAVALCANTE, Lília Iêda Chaves et al. Acolhimento institucional de crianças e adolescentes: teorias e evidências científicas para boas práticas. Curitiba: Juruá, 2018, p. 61-72.

SIQUEIRA, Aline Cardoso; DELL'AGLIO, Débora Dalbosco. O impacto da institucionalização na infância e na adolescência: uma revisão de literatura. Psicologia \& Sociedade, v. 18, n. 1, p. 7180, 2006.

SIQUEIRA, Aline Cardoso; DELL'AGLIO, Débora Dalbosco. Retornando para a família de origem: Fatores de risco e proteção no processo de reinserção de uma adolescente institucionalizada. Journal of Human Growth and Development, v. 17, n. 3, p. 134-146, 2007.

VASCONCELOS, Queila, Almeida; YUNES, Maria Angela Mattar; GARCIA, Narjara Mendes (2009). Um estudo ecológico sobre as interações da família com o abrigo. Paidéia (Ribeirão Preto) 19(43).

VASHCHENKO, Maryna; EASTERBROOKS, M. Ann; MILLER, Laurie C. Becoming their mother: Knowledge, attitudes, and practices of orphanage personnel in Ukraine. Infant Mental Health Journal, v. 31, n. 5, p. 570-590, 2010.

VIEIRA, Isabela Maciel; COUTINHO, Sabrine Mantuan dos Santos. Representações Sociais de Família para Adolescentes Institucionalizados em um Município Norte Fluminense. Revista Psicologia da IMED, Passo Fundo, vol. 11, n. 2, p. 34-50, jul-dez. 2019.

WENDT, Bruna; DELL'AGLIO, Débora Dalbosco. Práticas educativas positivas em contextos de acolhimento institucional: valorização dos méritos das crianças e adolescentes. In: CAVALCANTE, Lília Iêda Chaves et al. Acolhimento institucional de crianças e adolescentes: teorias e evidências científicas para boas práticas. Curitiba: Juruá, 2018, p. 189-204.

WEISZ, John; DURLAK, Joseph A.; SANDLER, Irwin N. Promoting and Protecting Youth Mental Health Through Evidence-Based Prevention and Treatment. American Psychological Association. Vol. 60, No. 6, 628-648 - October 2005.

WHO. World Health Organization. The Ottawa charter for health promotion. Geneve: 1986.

Submetido: $30 / 06 / 2021$

Aprovado: 16/08/2021 